\title{
Avaliação da remoção de cromo (III) por materiais compósitos porosos adsorventes de PE-g-MA, fibra de coco e quitosana, usando planejamento experimental
}

\author{
Evaluation of removal of chromium (III) by composite porous adsorbents \\ materials of PE-g-MA, coconut fiber and chitosan using experimental design
}

Dilma Alves Costa', Roberta Helena Mendonça², Mauro Meliga Wysard Junior ${ }^{3}$

\begin{abstract}
RESUMO
Os processos de adsorção podem ser empregados no tratamento de efluentes líquidos contendo metais pesados visando a reduzir os danos ambientais. Porém, o alto custo dos materiais adsorventes justifica a aplicação de adsorventes alternativos, como a fibra de coco (FC) e a quitosana (Q). Assim, este trabalho teve como objetivo desenvolver compósitos porosos adsorventes a partir da mistura de polietileno graftizado com anidrido maleico/FC/Q/NaCl, como agente porogênico (PE-g-MA/FC/Q/NaCl), e avaliar estatisticamente a capacidade de adsorção do cromo (III) em solução, com auxílio do software Statistica $5.0 \circledast$. Os resultados mostraram que a eficiência do processo sofreu influência das dimensões da FC, do teor de Q e do pH da solução contendo Cr (III). A capacidade máxima de remoção de Cr (III) por unidade de massa do compósito foi de 42,28 mg.'
\end{abstract}

Palavras-chave: fibra de coco; quitosana; compósitos poliméricos; adsorventes; cromo.

\begin{abstract}
Adsorption processes can be employed in the treatment of wastewater containing heavy metals to reduce environmental damage. However the high cost of adsorbent materials justifies the application of alternative adsorbents, such as coconut fiber (CF) and chitosan (C). Thus, this study aimed to develop porous composite adsorbents from the mixture of grafted maleic anhydride polyethylene/CF/C/ $\mathrm{NaCl}$, as porogen agent (PE-g-MA/CF/C/NaCl), and evaluate statistically adsorption capacity of chromium (III) solution, with the aid of software Statistica $5.0 \AA$. The results showed that the process efficiency was influenced by the size of the $\mathrm{CF}$, the content of $\mathrm{C}$ and the $\mathrm{pH}$ of the solution containing $\mathrm{Cr}$ (III). The maximum removal capacity of $\mathrm{Cr}$ (III) per unit mass of the composite was 42.28 mg.g
\end{abstract}

Keywords: coconut fiber; chitosan; polymeric composite; adsorbents chrome.

\section{INTRODUÇÃO}

A contaminação dos recursos hídricos por efluentes provenientes de diferentes ramos industriais é considerada um problema ambiental grave (ROY et al., 2004; HEMALATHA et al., 2011). Atividades industriais, como as indústrias químicas, de processamento de couro, de galvanoplastia e de corantes (HEMALATHA et al., 2011), podem gerar condições desfavoráveis ao meio ambiente, contribuindo muito para um aumento significativo das cargas tóxicas em águas.
Muitos metais são essenciais para o crescimento de todos os tipos de organismos, mas são requeridos em baixas concentrações, especialmente os metais-traço, os quais estão entre os contaminantes ambientais mais comuns e seu comportamento em diversos compartimentos ambientais merece destaque. Como exemplo, cita-se o cromo (Cr), que é encontrado nas formas trivalente $\mathrm{Cr}$ (III) e hexavalente $\mathrm{Cr}$ (VI), sendo considerado um metal essencial (quando trivalente); porém, em altas concentrações, pode ser prejudicial às atividades biológicas (vida humana, da fauna e da flora). Em virtude disso, a Resolução

'Professor titular do Departamento de Engenharia Química (DEQ), Instituto de Tecnologia (IT), Universidade Federal Rural do Rio de Janeiro (UFRRJ) - Seropédica (RJ), Brasil. 2Professor adjunto do DEQ/IT/UFRRJ - Seropédica (RJ), Brasil.

${ }^{3}$ Discente do Programa de Pós-Graduação em Engenharia Química (PPGEQ) do DEQ/IT/UFRRJ - Seropédica (RJ), Brasil.

Endereço para correspondência: Roberta Helena Mendonça - BR465, Km O7. Departamento de Engenharia Química, Campus UFRRJ - 23890-000 - Seropédica (RJ), Brasil -

E-mail: robertahelen@yahoo.com.br

Recebido: 17/06/13 - Aceito: 01/11/16 - Reg. ABES: 119214 
$n^{\circ}$ 357/2005 do Conselho Nacional do Meio Ambiente (CONAMA) estabeleceu a concentração máxima desse metal em água doce como sendo de 0,5 mg.L.-1 (OLIVEIRA \& MARINS, 2011; SOUZA et al., 2012; TOLEDO et al., 2013; SILVA et al., 2013).

Os metais considerados tóxicos (tais como cromo, zinco, cádmio, cobre e níquel, entre outros) representam um grupo de poluentes que requer um tratamento especial, pois não são degradados quimicamente e nem biologicamente. Ao contrário, são acumulados nas cadeias alimentares e estima-se que o tempo de residência deles esteja entre $15 \mathrm{e}$ 30 anos (ABD EL-REHIM et al., 2000; ROY et al., 2004; SIGNINI \& ARRUDA, 2010).

Vários métodos são utilizados para a remoção de metais pesados presentes na água, tais como: precipitação química, oxidação/redução, filtração, troca iônica, separação por membranas e adsorção. A adsorção tem sido a técnica mais frequentemente aplicada devido ao fato de haver uma variedade de materiais adsorventes de alta eficiência e com um custo relativamente baixo (ROY et al., 2004; HEMALATHA et al., 2011; SOUZA et al., 2012). Contudo, para que o processo de adsorção seja eficiente, os adsorventes escolhidos devem obedecer a alguns critérios, como: apresentar alta seletividade em relação ao adsorvato, alta capacidade de adsorção, longa vida, baixo custo e estar disponível no mercado em grandes quantidades (ROY et al., 2004; SOUZA et al., 2012).

Adsorventes podem ser definidos como sendo substâncias naturais ou sintéticas, que possuem alta energia superficial e que, ao apresentar uma estrutura interna porosa, potencializa as interações interfaciais entre o adsorvente e o adsorbato. Os adsorventes utilizados podem ser de origem mineral, orgânica ou biológica, como por exemplo: carvão ativado; algumas zeólitas; argilas; sílica; e materiais de baixo custo, como subprodutos e/ou resíduos industriais, biomassa e materiais poliméricos (ABD EL-REHIM et al., 2000; ROY et al., 2004; SIGNINI \& ARRUDA, 2010; HEMALATHA et al., 2011; PINO \& TOREM, 2011; SOUZA et al., 2012).

Dentre esses materiais, destacam-se como efetivos adsorventes de metais pesados as fibras vegetais (KALIA et al., 2011), particularmente: a fibra de coco (SOUSA et al., 2010; PINO \& TOREM, 2011; MAGALHÃES \& NEVES, 2011; SILVA et al., 2013), a quitosana (BARONI et al., 2005; CHAVES, 2009; SIGNINI \& ARRUDA, 2010; HEMALATHA et al., 2011; DAI et al., 2012), além de polímeros sintéticos modificados (ABD EL-REHIM et al., 2000; AKPEROV et al., 2011; KHATTAB \& SEDEEQ, 2012).

Na remoção de Cr (III) e Cr (VI), a fibra de coco (FC) e a quitosana (Q) têm sido bastante empregadas (NOMANBHAY \& PALANISAMY, 2005; BARONI et al., 2005; AZEVEDO et al., 2008; SIGNINI \& ARRUDA, 2010; PINO \& TOREM, 2011; MAGALHÃES \& NEVES, 2011; DAI et al., 2012; SILVA et al., 2013).

Em meio aquoso, o $\mathrm{Cr}$ se apresenta principalmente na forma de cromato $\left(\mathrm{CrO}_{4}^{2-}\right)$, dicromato $\left(\mathrm{Cr}_{2} \mathrm{O}_{7}^{2-}\right)$ e cromato de hidrogênio $\left(\mathrm{HCrO}_{4}^{-}\right)$.
Dependendo do $\mathrm{pH}$ do meio, o $\mathrm{Cr}$ assume diferentes estados de oxidação: em pH básico, predomina o $\mathrm{CrO}_{4}^{2-}$; em pH muito ácido (menor que 1), $\mathrm{o}_{2} \mathrm{CrO}_{4}$ prevalece; e, na faixa de 2 a 6, as espécies $\mathrm{HCrO}_{4}^{-} \mathrm{e}$ $\mathrm{Cr}_{2} \mathrm{O}_{7}^{2-}$ encontram-se em equilíbrio. A ocorrência do $\mathrm{Cr}$ (III) e do $\mathrm{Cr}$ (VI) se dá a partir de reações de oxidação e redução entre as duas espécies. Esse mecanismo depende do $\mathrm{pH}$, da concentração de oxigênio e dos redutores (TOLEDO et al., 2013).

Este trabalho teve o objetivo de desenvolver um material compósito poroso à base de FC, Q e polietileno de alta densidade, graftizado com anidrido maleico (PE-g-MA). A avaliação da capacidade absortiva desse novo material compósito visou à remoção de íons $\mathrm{Cr}$ (III) de soluções aquosas. Devido às suas propriedades características, FC e Q foram utilizadas como materiais adsorventes, para os quais o PE-g-MA foi utilizado como matriz de fixação. Dentre outros fatores, vislumbrou-se facilitar a remoção desses materiais após o processo adsortivo, devido às dimensões do material compósito, que podem variar de acordo com a demanda do processo - no presente trabalho foram utilizados compósitos na forma de discos (com diâmetro de $30 \mathrm{~mm}$ ) da FC $(0,09-0,3 \mathrm{~mm})$ e da Q in natura $(0,2-0,3 \mathrm{~mm})$. Para execução do trabalho, utilizou-se um planejamento experimental objetivando reduzir o número de experimentos a serem realizados e obter, com um índice de confiança de 95\% (IC95\%), um indicativo das principais condições (em termos de composição do compósito e pH de estudo) que afetam a capacidade adsortiva de íons $\mathrm{Cr}$ (III).

\section{METODOLOGIA}

Para obtenção dos materiais compósitos porosos foram utilizados: fibra de coco seca (FC) (Ecofibra Ltda) e quitosana (Q) - (Polymar Ltda - grau de desacetilação 0,97), com propriedades adsorventes; polietileno de alta densidade graftizado com anidro maleico (PE-gMA) - Polybond 3009 (Uniroyal - densidade a $23^{\circ} \mathrm{C}-0,95 \mathrm{~g} . \mathrm{cm}^{-3}$, nível de anidrido maleico $4,0 \%$ peso, ponto de fusão $-127^{\circ} \mathrm{C}$ ), como matriz polimérica; cloreto de sódio (Vetec Química Fina Ltda), utilizado como agente porogênico e nitrato de Cr (III) nonahidratado (Vetec Química Fina Ltda). A Figura 1 mostra uma representação esquemática da metodologia.

No pré-tratamento das FC, foram utilizadas três faixas granulométricas de FC: 0,097-0,142; 0,183-0,234 e 0,290-0,318 mm (faixas 1, 2 e 3 ) (PINO \& TOREM, 2011; MAGALHÃES \& NEVES, 2011), obtidas em moinho de facas e classificadas com o auxílio de peneiras Tyler-Standart.

Os materiais compósitos identificados por CFCiQ/j (em que: “i” corresponde à variação da granulometria de FC; e “j” corresponde à massa, em gramas, de Q) foram preparados a partir das misturas físicas de PE-g-MA/FC/Q/NaCl, em reômetro de torque Themo Scientyfic, modelo PolyLab QC, com rotor modelo roller, a $140^{\circ} \mathrm{C}, 10 \mathrm{~min}$ e 60 rpm (REDIGHIERI, 2006). A proporção de PE-g-MA/FC nas misturas foi fixada em 60/40\% (m/m). A massa de cloreto de sódio $(\mathrm{NaCl})$, 
agente porogênico, correspondeu a $50 \%$ do somatório das massas de FC e PE-g-MA (MENDONÇA et al., 2009; MEIGA, 2010). A proporção de quitosana foi fixada entre $3,5-21,5 \%(1,4 ; 2,5 ; 5,0 ; 7,5 ; 8,6 \mathrm{~g}) \mathrm{da}$ massa total dos componentes utilizados, de acordo com o planejamento experimental e a fim de viabilizar economicamente o material desenvolvido. A massa total dos componentes respeitou o volume máximo de segurança da câmara de mistura de 40,0 g.

As pastilhas de $\mathrm{CFCiQ} / \mathrm{j}$ de 1,0-2,0 mm de espessura foram obtidas por meio da prensagem das misturas em prensa térmica e hidráulica (marca SOLAB, modelo SL11), a $140^{\circ} \mathrm{C}$ e 205,2 kgf.cm-2, durante 15 min., e lixiviadas para obtenção dos poros, com a solubilização do $\mathrm{NaCl}$ em água deionizada com agitação mecânica de $80 \mathrm{rpm}$, por $72 \mathrm{~h}$ (MENDONÇA, 2009; MEIGA, 2010). Após esse tempo, todas as peças foram secas à temperatura ambiente e pesadas até atingirem massa constante.

De acordo com a literatura, a granulometria da FC (PINO \& TOREM, 2011; MAGALHÃES \& NEVES, 2011) e o pH da solução adsortiva (SIGNINI \& ARRUDA, 2010; HEMALATHA et al., 2011; PINO \& TOREM, 2011; TALOKAR., 2011; SOUZA et al., 2012; TOLEDO et al., 2013) tendem a interferir no processo de adsorção.

A influência das variáveis (granulometria de FC, quantidade de $\mathrm{Q}$ e pH da solução contendo o adsorvato $\mathrm{Cr}$ (III)) foi investigada a partir de um planejamento fatorial completo $2^{\mathrm{k}}=2^{2}$ (BRASIL et al., 2007), para cada faixa de granulometria da FC, resultando em três planejamentos, com a quantidade de Q presente nos materiais compósitos e o $\mathrm{pH}$ da solução adsortiva de $\mathrm{Cr}$ (III) sendo consideradas variáveis independentes. Esse planejamento foi realizado para identificar quais variáveis são significativas para um valor p inferior a 0,05 e IC95\%, e quais os melhores níveis a serem utilizados (LIMA, 2013; BRASIL et al., 2007, MIOR et al., 2013). A Tabela 1 mostra os níveis utilizados nos planejamentos nas três faixas granulométricas (1, 2 e 3) e os valores de massa de Q e pH de estudo associados a cada nível.

Os materiais compósitos de CFCiQ/j foram analisados por difração de raios X (DRX) (difratrômetro RIGAKU), utilizando radiação K $\alpha$ de cobre, varredura a $0,2^{\circ}(2 \theta)$ por minuto, método contínuo, $30 \mathrm{kV}$ e $15 \mathrm{~mA}$, ângulos inicial e final de $10^{\circ}$ e $40^{\circ}(2 \theta)$, respectivamente, a fim de identificar a influência da granulometria de FC e da quantidade de Q nas intensidades dos picos cristalinos dos materiais compósitos porosos. Também foi possível calcular o grau de cristalinidade Xc desses materiais em função das áreas correspondentes aos picos cristalinos e ao halo amorfo (pico alargado sob os picos cristalinos) a partir da Equação 1 (MUCCILLO, 2009; SALMORIA et al., 2008; SANDER, 2010), utilizando o programa Origin ${ }^{\circledR}$ versão 6.0 para elaboração das curvas e cálculo das integrais.

$X c=A_{c} \cdot\left(A_{c}+A_{\mathrm{a}}\right)^{-1} \times 100$

Em que:

$A_{\mathrm{c}}$ representa a soma das áreas dos picos cristalinos; e

$A_{\mathrm{a}}$ corresponde à área do halo amorfo.

As áreas são calculadas a partir das curvas de DRX.

As análises de adsorção com as pastilhas de (CFCiQ/j) foram realizadas com soluções de $100 \mathrm{mg} \cdot \mathrm{L}^{-1}$ de $\mathrm{Cr}^{+3}$, a partir de nitrato de cromo (SIGNINI \& ARRUDA, 2010; MAGALHÃES \& NEVES, 2011),

Tabela 1 - Níveis utilizados nos planejamentos nas três faixas granulométricas.

\begin{tabular}{l|c|c|c|c|c}
\hline Níveis & $-1,41$ & -1 & 0 & 1 & 1,41 \\
\hline Massa de quitosana (g) & 1,40 & 2,50 & 5,00 & 7,50 & 8,60 \\
\hline pH da solução de $\mathrm{Cr}$ (III) & 4,70 & 5,00 & 5,75 & 6,50 & 6,90 \\
\hline
\end{tabular}

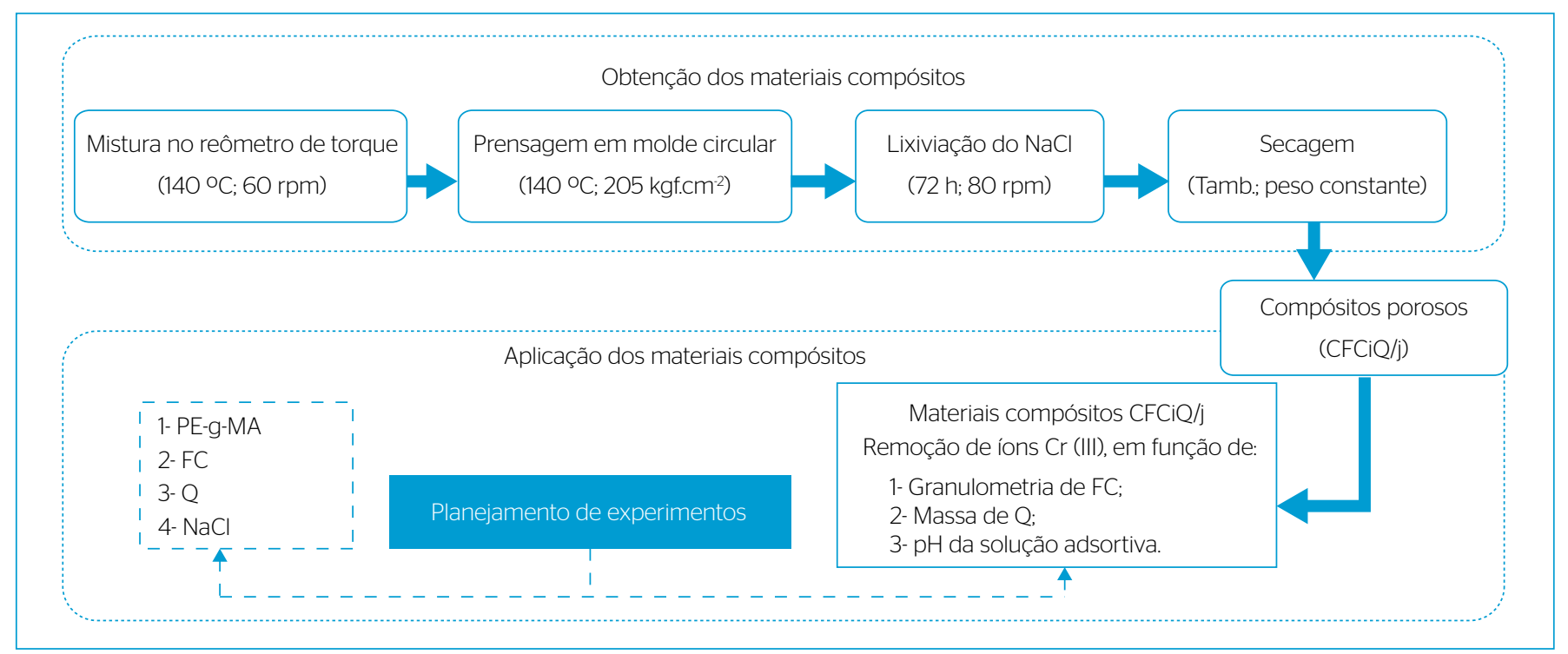

Figura 1 - Representação esquemática da metodologia. 
em diferentes valores de $\mathrm{pH}(4,7 ; 5,0 ; 5,75 ; 6,5$ e 6,9), definidos com base em um planejamento experimental (com auxílio do software Statistica $5.0^{\circ}$ ), levando em consideração o diagrama de complexação dos íons $\mathrm{Cr}$ (III) em função do $\mathrm{pH}$ e os limites dos valores de $\mathrm{pH}$ no ponto de carga neutra $\left(\mathrm{pH}_{z \mathrm{pc}}\right.$ ) das FC e da Q (MALTEZ; 2003; VIEIRA, 2004; SOUZA, 2009; PINO \& TOREM, 2011).

Os materiais puros PE-g-MA, FC (nos intervalos de granulometrias de 0,097-0,142 e 0,183-0,234 mm) e Q também foram analisados, nas mesmas condições utilizadas para as pastilhas de $(\mathrm{CFCiQ} / \mathrm{j})$, com a finalidade de avaliar seus comportamentos como adsorventes.

Os sistemas compostos pelas pastilhas de $(\mathrm{CFCiQ} / \mathrm{j})$ imersas nas diferentes soluções contendo o adsorvato $\mathrm{Cr}$ (III) foram submetidos à agitação mecânica constante (120 rpm) durante 1 h, com agitador da marca IKA, modelo RW 20 (HEMALATHA et al., 2011). A capacidade de adsorção do adsorvente, $Q_{\mathrm{e}}$ (mg do metal.g ${ }^{-1}$ do adsorvente), pode ser quantificada com base na diferença de concentração dos íons metálicos antes e após o processo de adsorção, usando-se a Equação 2 (MOREIRA et al., 2007; SOUZA et al., 2012; TOLEDO et al., 2013). As concentrações das soluções foram quantificadas pelo método de absorção atômica

$Q e=[(\mathrm{Co}-\mathrm{Ce}) \cdot V] \cdot \mathrm{m}^{-1}$

Em que:

Co é concentração do soluto na solução inicial (mg/L);

Ce é a concentração do soluto no equilíbrio $(\mathrm{mg} / \mathrm{L})$;

$V$, volume da solução (L); e

$m$, massa do adsorvente (g).

A porcentagem de adsorção do metal estudado foi obtida através da Equação 3 (SILVA et al., 2011).

$\%$ Adsorção $=[(\mathrm{Co}-\mathrm{Ce}) \cdot 100] \cdot \mathrm{C} \mathrm{e}^{-1}$

Após as análises de adsorção, as pastilhas de $(\mathrm{CFCiQ} / \mathrm{j})$ foram analisadas por microscopia eletrônica de varredura (MEV) e espectroscopia de energia dispersiva (EDS), com o intuito de detectar a presença de $\mathrm{Cr}$ (III) na superfície dos materiais compósitos. As micrografias foram obtidas em um Microscópio Eletrônico de Varredura (MEV) JEOL JSM, modelo 6460 LV (Laboratório de Microscopia Eletrônica do PEMM/COPPE), na voltagem de $15 \mathrm{KV}$. Todas as amostras foram fraturadas criogenicamente e previamente recobertas com carbono, antes de serem analisadas.

\section{RESULTADOS E DISCUSSÕES}

Compósitos poliméricos constituídos de poliolefinas funcionalizadas (PE-g-MA ou PP-g-MA) e FC apresentam boa compatibilidade entre as fases (matriz e fase dispersa) devido à possível formação de ligações covalentes entre os grupos anidrido reativos do polímero funcionalizado e os grupos hidroxila das cadeias de celulose presentes na fase dispersa. Além das ligações covalentes, interações do tipo ligações de hidrogênio também podem ser formadas (Figura 2) e, consequentemente, promovem a adesão entre as fases (OLIVEIRA et al., 2010; ALBINANTE et al., 2013; SANTOS et al., 2014).

No presente trabalho as curvas de torque (Figura 3) obtidas no preparo dos materiais compósitos porosos $(\mathrm{CFCiQ} / \mathrm{j})$, nas diferentes granulometrias de FC, apresentam o aumento nos valores de torque no intervalo de tempo entre 5,0 e 6,0 min (metade do tempo de mistura) para todas as curvas, causado pela adição de Q. A adição do biopolímero na metade do tempo de mistura foi adotada para evitar a possível degradação térmica do material. Os valores de torque constantes após a adição de $\mathrm{Q}$ foram atribuídos à melhor homogeneidade das misturas (COUTINHO et al., 2007); isto é, à fusão dos componentes poliméricos e à boa dispersão das FC (fase dispersa) na matriz polimérica de PE-g-MA, devido à interação entre os grupos ativos do anidrido maleico presentes no PE-g-MA, com os grupos hidroxila das fibras de celulose (OLIVEIRA et al., 2010; SANTOS et al., 2014) e grupos hidroxila e/ou aminas presentes na Q (SALMAH \& AZIEYANTI, 2011).

A Figura 4 mostra a fotografia de duas pastilhas de compósitos de $(\mathrm{CFCiQ} / \mathrm{j})$ obtidos com a maior faixa granulométrica de FC $(0,290-0,318 \mathrm{~mm})$. É possível observar, macroscopicamente, que o tamanho da FC afeta as características da superfície dos materiais compósitos.

O planejamento fatorial completo $2^{2}$ foi de grande importância, em relação à minimização de esforços e do tempo experimental. Assim, as etapas experimentais foram pautadas na variação dos teores de $\mathrm{Q}$ e em diferentes valores de $\mathrm{pH}$, com a finalidade da obtenção de uma resposta específica da capacidade de remoção de íons $\mathrm{Cr}$ (III) (mg.g ${ }^{-1}$ ) pelos materiais compósitos porosos $\mathrm{CFCiQ/j}$ (Tabela 2).

Analisando os resultados apresentados na Tabela 2, pode-se verificar que nos experimentos 04 e 06 as variáveis ( $\mathrm{pH}$ e Q) apresentaram um efeito máximo positivo para a remoção de $\mathrm{Cr}$ (III), para todas as faixas granulométricas, mostrando que altos teores de Q nos compósitos

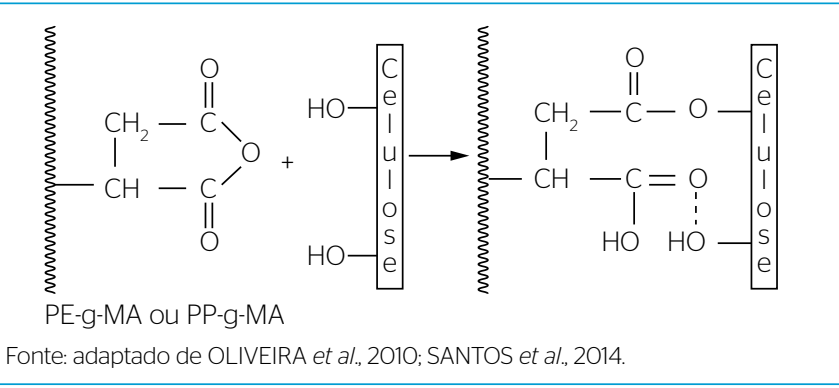

Figura 2 - Mecanismo de acoplamento do polietileno ou polipropileno graftizados com anidrido maleico (PE-g-MA ou PP-g-MA) com fibras celulósicas. 
$\mathrm{CFCiQ} / \mathrm{j}$ e valores altos de $\mathrm{pH}$ da solução adsortiva contribuem para um processo de adsorção mais eficiente. Além disso, a granulometria da FC influenciou na capacidade de adsorção desse material (como visualizado pelo experimento 07), com o compósito obtido na menor proporção de Q. A faixa de menor granulometria da FC (faixa 1) se mostrou menos favorável ao processo de remoção de Cr (III). Esse resultado pode estar associado ao $\mathrm{pH}$ mais baixo (igual a 5,75) que interfere na eficiência da remoção de Cr (III). Para os compósitos contendo maiores massas de Q
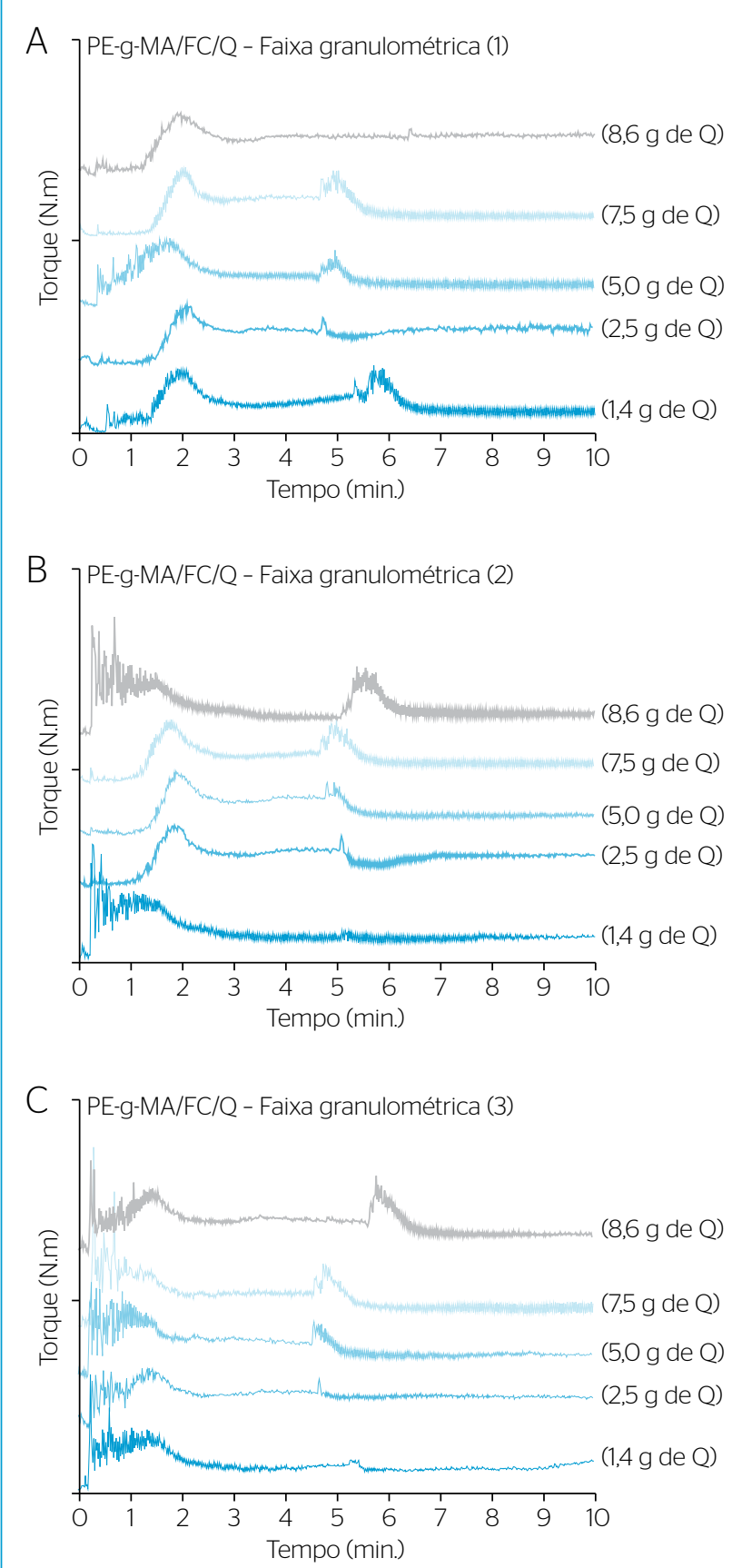

Figura 3 - Curvas de torque dos materiais compósitos de (CFCiQ/j) obtidas durante o preparo, nas diferentes faixas granulométricas: (A) faixa 1; (B) faixa 2; (C) faixa 3. $\cong 8,6$ g (experimento 08), os resultados obtidos mostraram que maiores quantidades de $\mathrm{Q}$, no mesmo $\mathrm{pH}$, auxiliam no processo de adsorção da FC de menor granulometria. Esse comportamento dos compósitos obtidos com a FC na faixa granulométrica 1 pode ser atribuído a uma maior homogeneidade e distribuição dos elementos adsortivos (FC e Q) na matriz polimérica, possibilitando maior dispersão e exposição dos sítios ativos em toda a área do material confeccionado.

A maior capacidade de remoção ocorreu em níveis máximos de $\mathrm{pH}$. A partir do $\mathrm{pH}$ 6,5 ocorreu um aumento bastante significativo da remoção de Cr. Esse resultado foi relacionado à eficiência da adsorção dos íons Cr (III) pelos adsorventes (FC e Q), levando à conclusão de que uma maior quantidade de sítios ativos (grupos funcionais $\mathrm{OH}, \mathrm{C}=\mathrm{O}, \mathrm{C}-\mathrm{O}$ ) presentes na estrutura química da FC encontra-se dissociada e com cargas negativas (valores mais elevados de $\mathrm{pH}$ ). Consequentemente, apresentam maior afinidade pelos cátions metálicos. Pino e Torem (2011) verificaram que a adsorção do Cr (III) foi favorecida pelo aumento do $\mathrm{pH}(6,0-9,0)$, quando utilizaram o pó da casca de coco como biossorvente, assim como Uchoa et al. (2007), que observaram que a maior eficiência da FC como adsorvente de $\mathrm{Cr}$

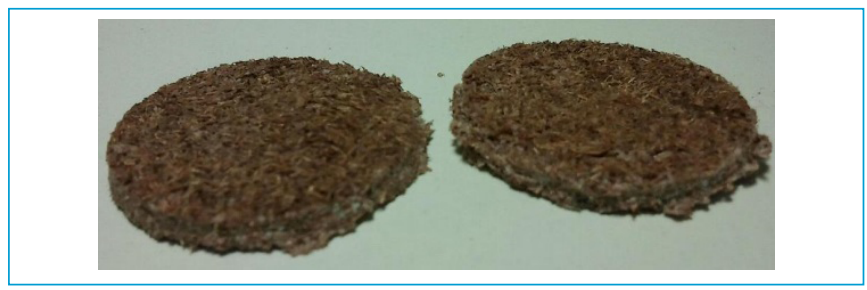

Figura 4 - Fotografia de compósitos porosos de (CFCiQ/j) obtidos com FC na faixa granulométrica $3(0,290-0,318 \mathrm{~mm})$.

Tabela 2 - Capacidade de remoção de $\mathrm{Cr}$ (III) $\left(\mathrm{mg} \mathrm{g}^{-1}\right)$ pelos materiais $\mathrm{CFCiQ} / \mathrm{j}$, de acordo com o planejamento fatorial completo para duas variáveis $\left(2^{2}\right)$.

\begin{tabular}{c|c|c|c|c|c|c|c}
\multirow{2}{*}{ Ensaios } & \multicolumn{3}{|c|}{$\begin{array}{c}\text { Planejamento } \\
\text { experimental }\end{array}$} & \multicolumn{4}{|c}{$\begin{array}{r}\text { Resultados experimentais de Q } \\
\text { (mg.-1) }\end{array}$} \\
\cline { 2 - 8 } & $\mathbf{x} 1$ & $\mathrm{x} 2$ & $\mathrm{pH}$ & $\mathrm{Q}(\mathrm{g})$ & $\mathrm{CFC1Q} / \mathrm{j}$ & $\mathrm{CFC2Q} / \mathrm{j}$ & CFC3/Qj \\
\hline 1 & -1 & -1 & 5,00 & 2,50 & 5,94 & 10,58 & 4,99 \\
\hline 2 & 1 & -1 & 6,50 & 2,50 & 24,39 & 24,13 & 27,33 \\
\hline 3 & -1 & 1 & 5,00 & 7,50 & 7,31 & 6,93 & 5,37 \\
\hline 4 & 1 & 1 & 6,50 & 7,50 & 41,48 & 29,34 & 31,84 \\
\hline 5 & $-1,41$ & 0 & 4,70 & 5,00 & 7,45 & 7,31 & 5,06 \\
\hline 6 & 1,41 & 0 & 6,90 & 5,00 & 42,28 & 29,40 & 28,46 \\
\hline 7 & 0 & $-1,41$ & 5,75 & 1,40 & 18,88 & 42,78 & 31,85 \\
\hline 8 & 0 & 1,41 & 5,75 & 8,60 & 26,28 & 17,67 & 17,18 \\
\hline 9 & 0 & 0 & 5,75 & 5,00 & 15,50 & 10,27 & 15,25 \\
\hline 10 & 0 & 0 & 5,75 & 5,00 & 11,65 & 9,77 & 20,22 \\
\hline 11 & 0 & 0 & 5,75 & 5,00 & 14,15 & 7,51 & 14,09 \\
\hline
\end{tabular}

i: faixa 1 (0,097-0,142); faixa 2 (0,183-0,234/0); faixa 3 (0,290-0,318 mm), em que i corresponde à faixa granulométrica da FC; j: massa de quitosana (Q), em gramas. 
(III) ocorreu em pH 5,0. O mesmo raciocínio foi usado para interpretar a atuação da Q como material adsorvente, pois em $\mathrm{pH}$ de 6,0 a 7,0 o grupo $\mathrm{NH}_{2}$ da $\mathrm{Q}$ encontra-se desprotonado, aumentando a probabilidade de quelação dos íons Cr (III) pelos sítios ativos (VIANA \& GAUBEUR, 2009; DAI et al., 2012), mesmo que para pH mais altos (acima de 7,0) haja também a probabilidade do início da complexação de íons Cr (III), como verificado pelos pesquisadores Pino e Torem (2011), Hermes et al. (2009) e Giovannini et al. (2008).

De acordo com os resultados do planejamento experimental, deve-se utilizar níveis de $\mathrm{pH}$ maiores para potencializar o processo de adsorção; porém existe a tendência de ocorrer a complexação e a precipitação do $\mathrm{Cr}$ em valores de $\mathrm{pH}$ acima de 7,0 (KOTAŚ \& STASICKA, 2000) e, dessa forma, os efeitos adsortivos dos compósitos seriam mascarados.

Os fatores mais significativos na capacidade de remoção de Cr (III) pelos materiais compósitos porosos de $\mathrm{CFCiQ} / \mathrm{j}$ para os experimentos $\mathrm{e}$ suas combinações, nas três faixas granulométricas, foram: $\mathrm{pH}$ (linear), para os ensaios realizados nas faixas granulométricas 1, 2 e 3; $\mathrm{pH}$ (quadrático); e Q (quadrática), que também se mostrou significativa para a faixa granulométrica 2. A Q foi a segunda variável mais relevante: a variável quitosana quadrática $\mathrm{Qa}(\mathrm{Q})$ atingiu um grau de significância aceitável pelo programa, referente aos experimentos realizados na faixa granulométrica 2 da FC.

A partir dos fatores e combinações desses significativos para a variável de resposta ( $\mathrm{pH}$ para as faixas granulométricas 1 e 3; e $\mathrm{pH}$, $\mathrm{pH}^{2}$ e $\mathrm{Q}^{2}$ para a faixa granulométrica 2), foram elaborados modelos matemáticos simples para o processo de adsorção, pela análise da significância estatística dos coeficientes de regressão de equações inicialmente completas, propostas para as três faixas granulométricas estudadas, obtendo-se as Equações 4, 5 e 6.

$\mathrm{Y}_{1}=(13,78 \pm 1,8)+(12,75 \pm 1,1)^{\star} \mathrm{X}_{1}+(4,56 \pm 1,31)^{\star} \mathrm{X}_{1}^{2}+$

$(3,62 \pm 1,1)^{\star} X_{2}+(3,4 \pm 1,31)^{\star} X_{2}^{2}$

$Y_{2}=(9,20 \pm 4,2)+(8,41 \pm 2,5)^{\star} X_{1}+(8,9 \pm 3,08)^{\star} X_{2}^{2}$

$\mathrm{Y}_{3}=(16,53 \pm 3,21)+(10,25 \pm 1,97)^{\star} \mathrm{X}_{1}$

Em que:

Y é igual à remoção de $\mathrm{Cr}$ (III) nas diferentes faixas granulométricas; $\mathrm{X}_{1}$ equivale ao $\mathrm{pH}$ da solução adsortiva; $\mathrm{e}$

$\mathrm{X}_{2}$ corresponde à massa de quitosana $(\mathrm{Q})$, em valores codificados.

A Figura 5 apresenta a relação entre os valores experimentais e os valores preditos pelo modelo.

Mesmo ocorrendo pouca dispersão em torno da reta ideal $\mathrm{Y}_{\text {pred }}=\mathrm{Y}_{\text {obs' }}$, procedeu-se à análise de variância (ANOVA), com realização do teste $\mathrm{F}$, segundo o qual o valor de $\mathrm{F}$ calculado $\left(\mathrm{F}_{\text {calculado }}\right)$, definido como a relação entre a média quadrática da regressão e a do resíduo, deve ser maior que o valor tabelado de $\mathrm{F}\left(\mathrm{F}_{\text {tabelado }}\right)$, para validar o modelo matemático. Pelos dados da Tabela 3, verificou-se que o valor de $\mathrm{F}_{\text {calculado }}$ foi
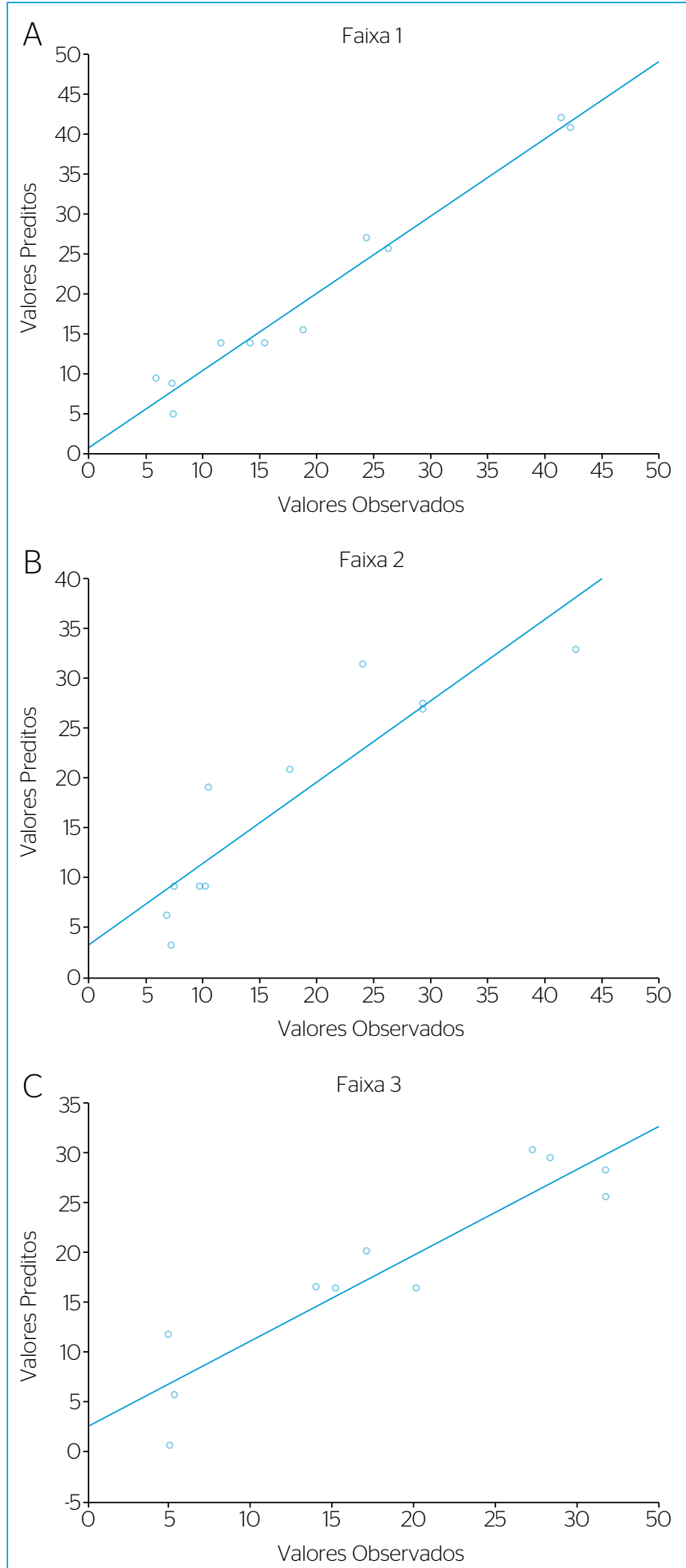

Figura 5 - Relação entre os valores experimentais e os valores preditos pelo modelo, de remoção de $\mathrm{Cr}$ (III) pelos compósitos porosos de $\mathrm{CFCiQ} / \mathrm{j}$, para a faixa granulométrica: a) $1(0,097-0,142 \mathrm{~mm})$; b) $2(0,183-0,234 \mathrm{~mm})$ c) $3(0,290-0,318 \mathrm{~mm})$. 
maior que o valor de $\mathrm{F}_{\text {tabelado }}$, podendo-se, por esse critério, validar o modelo matemático.

A Figura 6 apresenta as superfícies de resposta dos três planejamentos geradas a partir das Equações 7, 8 e 9, para as faixas granulométricas 1,2 e 3 , respectivamente.

$\mathrm{Y}_{1}=13,78+12,75^{\star} \mathrm{X}_{1}+4,56^{\star} \mathrm{X}_{1}^{2}+3,62^{\star} \mathrm{X}_{2}+3,41^{\star} \mathrm{X}_{2}^{2}+3,93^{\star} \mathrm{X}_{1}^{\star} \mathrm{X}_{2}$

$Y_{2}=9,20+8,41^{\star} X_{1}+2,93^{\star} X_{1}^{2}-4,24^{\star} X_{2}+8,90^{\star} X_{2}^{2}+2,21^{\star} X_{1}^{\star} X_{2}$

$Y_{3}=16,53+10,25^{\star} X_{1}-0,71^{\star} X_{1}^{2}-1,98^{\star} X_{2}+3,19^{\star} X_{2}^{2}+1,032^{\star} X_{1}^{\star} X_{2}(9)$

Tais superfícies apresentam a remoção de Cr (III) em função das massas de $\mathrm{Q}$ presentes nos compósitos $(\mathrm{CFCiQ} / \mathrm{j})$ e o $\mathrm{pH}$ da solução adsortiva, contendo íons de $\mathrm{Cr}$ (III). Pode-se observar, pelas Figuras 6A, 6B e 6C, que a região mais escura (indicada por seta) representa uma tendência aos valores mais altos de remoção de Cr (III), se aumentados os valores da quantidade de $\mathrm{Q}$ e do $\mathrm{pH}$ da solução adsortiva, como verificado experimentalmente.

A partir da observação das superfícies de resposta geradas, pode-se comprovar a influência das variáveis $(\mathrm{pH}$, granulometria da FC e massa de Q) na adsorção de Cr (III), tendendo para maior eficiência no processo de adsorção, com o aumento dessas variáveis, para as três faixas granulométricas da FC. Além disso, o aumento da faixa granulométrica, como já visualizado pelos resultados da Tabela 2, favorece a adsorção para valores de $\mathrm{pH}$ acima de 5,75 $(5,75 ; 6,5$ e 6,9) independentemente da quantidade de Q presente nos materiais compósitos. O mesmo comportamento foi verificado quando utilizamos compósitos que não fizeram parte do planejamento, mas foram utilizados para medida de comparação, compósito sem Q (CFCiQ/0) e com maior teor de Q (CFC2Q/10).

Para confirmar a presença do metal Cr nas superfícies de alguns $\mathrm{CFCiQ} / \mathrm{j}$, foi realizada a análise de difração de raios-X (DRX), possibilitando a determinação do grau de cristalinidade das amostras que apresentaram a melhor capacidade de adsorção (ensaios 4 e 6) de íons Cr (III) (Figura 7).

Todos os difratogramas dos compósitos porosos $\mathrm{CFCiQ} / \mathrm{j}$ apresentaram os picos de cristalinidade relacionados à matriz polimérica de polietileno graftizado (PE-g-MA), em torno de 21,6 e

Tabela 3 - Valores de $F_{\text {calculado }}$ e $F_{\text {tabelado }}$ obtidos por meio do cálculo da ANOVA.

\begin{tabular}{l|c|c} 
& $\boldsymbol{F}_{\text {calculado }}$ & $\boldsymbol{F}_{\text {tabelado }}$ \\
\hline Faixa 1 & 20,99312 & 4,533677 \\
\hline Faixa 2 & 8,03989 & 4,45897 \\
\hline Faixa 3 & 30,61163 & 5,117355 \\
\hline
\end{tabular}

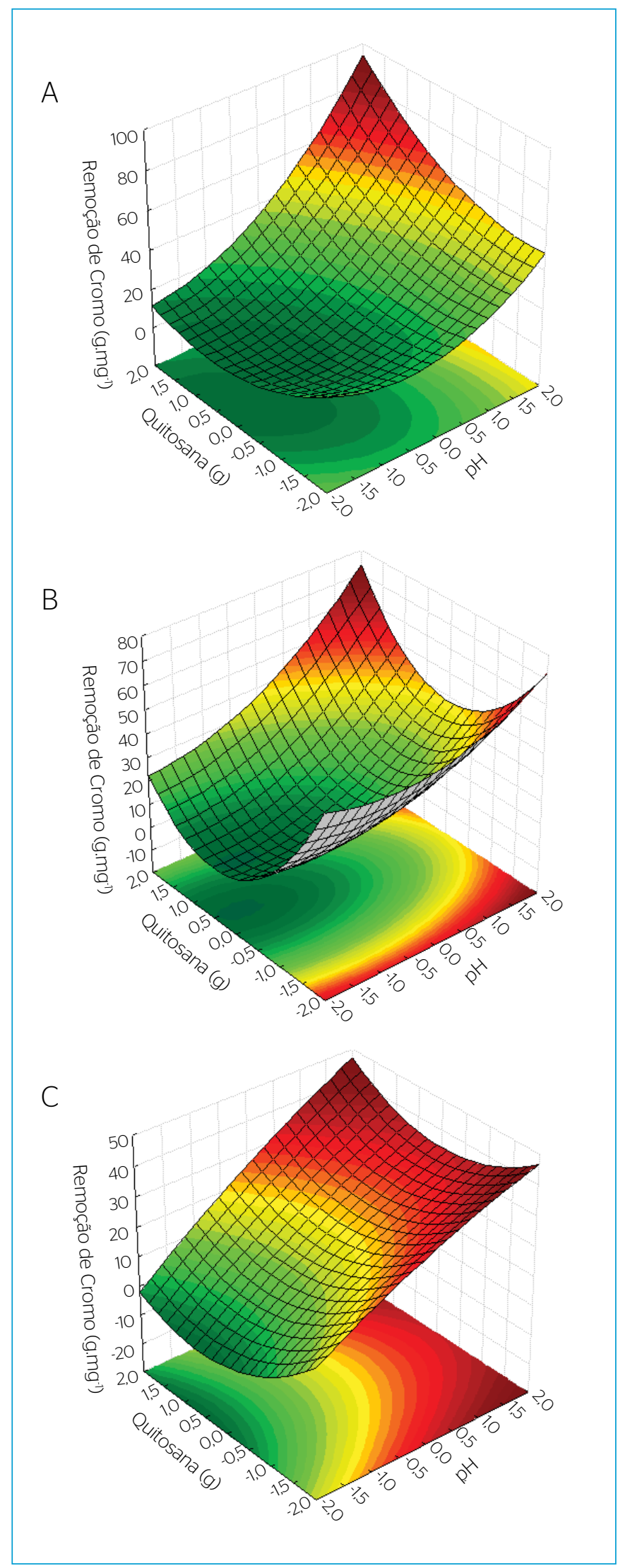

Figura 6 - Superficies de resposta para a remoção de $\mathrm{Cr}$ (III) em função do $\mathrm{pH}$ e da massa de quitosana, nas faixas: a) $1(0,097-0,142 \mathrm{~mm})$; b) $2(0,183-0,234 \mathrm{~mm})$; c) $3(0,290-0,318 \mathrm{~mm})$. 

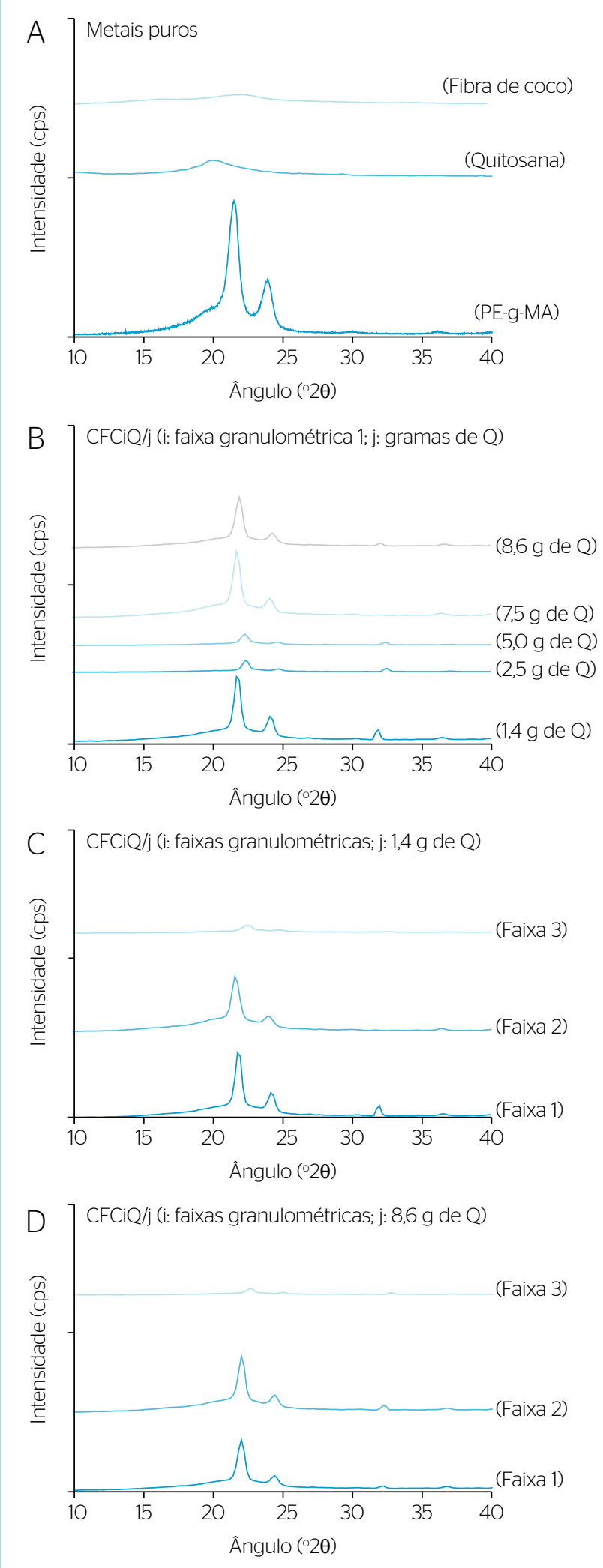

Figura 7 - Curvas de DRX: a) materiais puros (PE-g-MA, Q e FC) e dos materiais compósitos de (CFCiQ/j); b) faixa granulométrica 1 e variação da quantidade de $\mathrm{Q} ; \mathrm{c}$ ) três diferentes faixas granulométricas, e contendo $1,4 \mathrm{~g}$ Q; d) três diferentes faixas granulométricas, e contendo 8,6 g Q. $23,7^{\circ}(2 \theta)$ e grau de cristalinidade $\cong 53,9 \%$ (REDIGHIERI, 2006), indicando que os compósitos também apresentam cristalinidade, mesmo na presença de FC e Q, que apresentam baixas cristalinidades (Figura 4A). Os picos de difração dos materiais compósitos de $\mathrm{CFCiQ} / \mathrm{j}$, no entanto, apresentaram intensidades bem menores do que a intensidade da matriz polimérica pura (PE-g-MA). A diminuição da intensidade dos picos foi atribuída à maior homogeneidade das misturas, em consequência das interações formadas entre os grupos anidrido maleico presentes na matriz de polietileno graftizado, com os grupos hidroxila e carboxila da FC e os grupos carbonila e $\mathrm{NH}_{2}$, da Q (Figura 4B). Pode-se visualizar também, nas Figuras 4C e 4D, a influência da granulometria da FC na cristalinidade da matriz semicristalina do PE-g-MA, mostrada pela diminuição da intensidade dos picos de difração, para menores ou maiores quantidades de Q. Esse comportamento foi atribuído à desorganização das cadeias de PE-g-MA, devido ao tamanho das fibras de FC. A Figura 8 apresenta as micrografias de EDS dos materiais adsortivos após o processo de adsorção de Cr (III).

Pode-se observar nas micrografias de EDS pequenos pontos esbranquiçados, os quais foram atribuídos à deposição dos íons Cr (III) nas superfícies dos materiais compósitos, assim como verificado por Pino (2005) e Silva et al. (2013). Também pode ser observada a presença dos elementos sódio e cloro, atribuídos ao resíduo do sal $\mathrm{NaCl}$ utilizado como agente porogênico. A confirmação da presença do Cr (III) em algumas amostras de CFCiQ/j foi dada pela presença e identificação das bandas dos elementos presentes em suas superfícies.

\section{CONCLUSÕES}

Baseado nos resultados obtidos neste estudo, as seguintes conclusões podem ser feitas:

- O planejamento de experimentos adotado foi útil para analisar a influência das variáveis $\mathrm{pH}$, granulometria da FC e massa de Q sobre o processo de adsorção de Cr (III) de soluções aquosas contendo esse íon;

- Há uma tendência de maior eficiência no processo de adsorção, com o aumento do $\mathrm{pH}$, na menor faixa granulométrica da FC, em diferentes teores de $\mathrm{Q}$, como mostrado nas superfícies de resposta geradas pelos modelos matemáticos;

- Os resultados obtidos foram relacionados à eficiência da FC e da Q em adsorver íons $\mathrm{Cr}$ (III), em valores de $\mathrm{pH}$ mais elevados. A presença de sítios ativos dissociados e/ou desprotonados na FC e na Q - em pH's de 6,0-7,0 — aumenta a probabilidade de adsorção dos íons Cr (III) por esses sítios ativos;

- Nos compósitos sem Q e naqueles com maiores teores de Q há uma tendência de melhoria significava do processo de adsorção 
$15 \longrightarrow 66635$

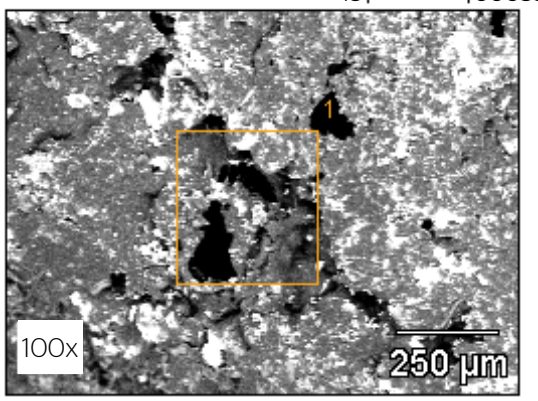

$15 \square 6636$
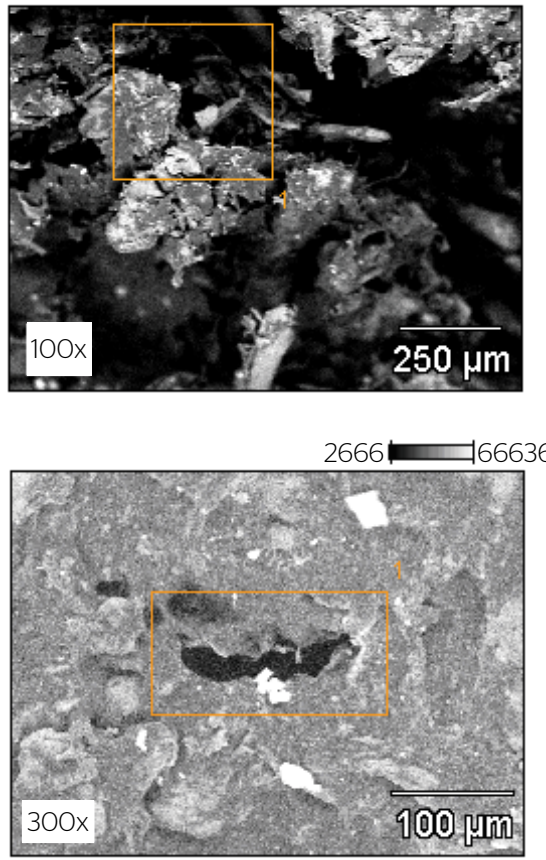

1109

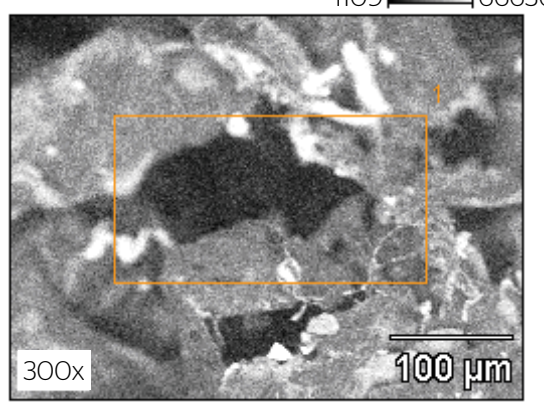

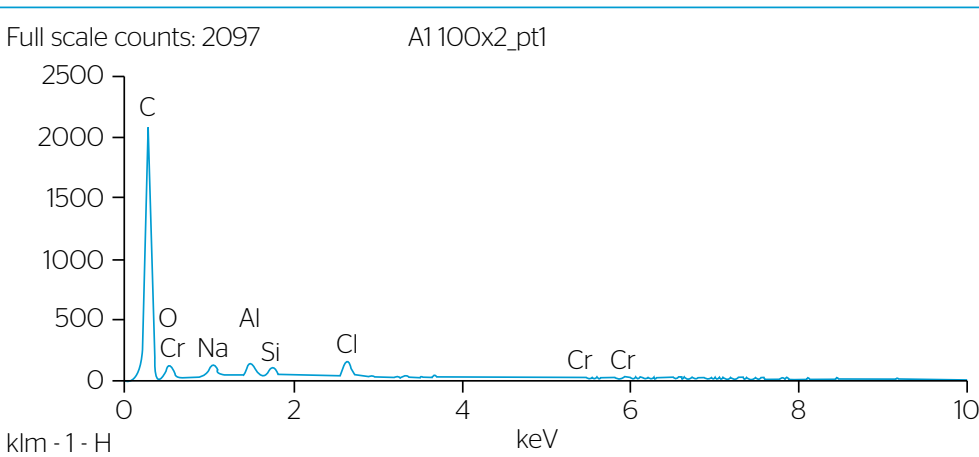

Full scale counts: $2014 \quad$ B1 100x1_pt1

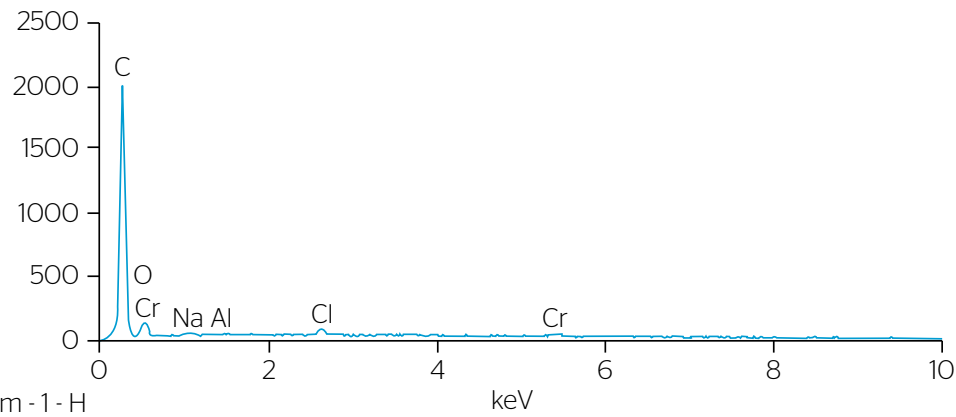

Full scale counts: $2012 \quad$ 5B 300x1_pt1

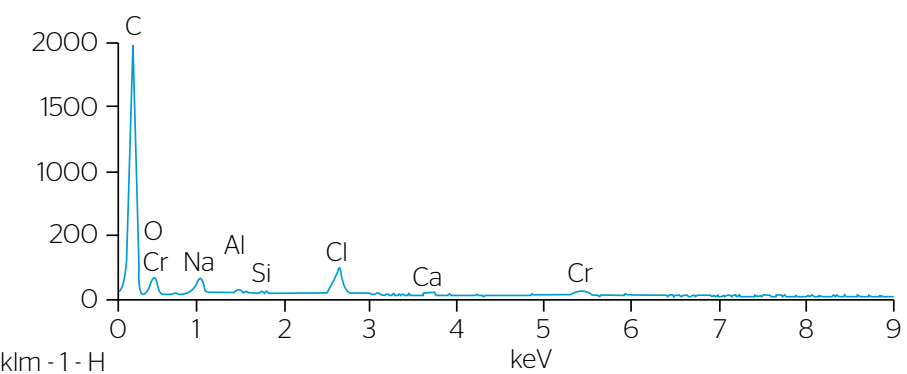

Full scale counts: $2008 \quad$ 6B 300x1_pt1

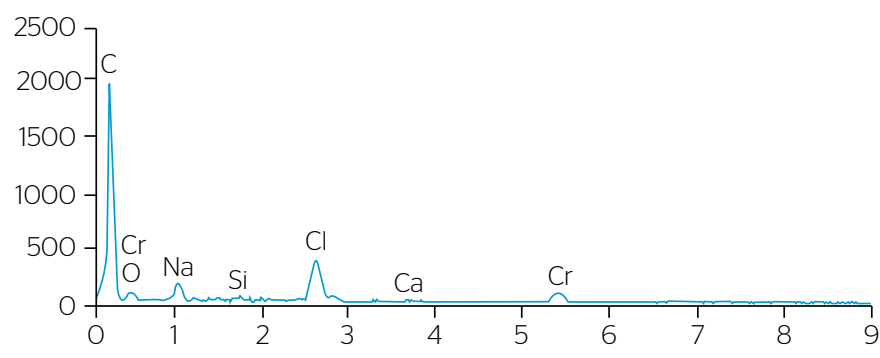

$\mathrm{klm}-1-\mathrm{H}$

keV

Figura 8 - Micrografia (EDS), contendo as bandas representativas dos elementos presentes no material compósito: a) CFC10/O, após o processo adsortivo de $\mathrm{Cr}$ (III), em pH 5,75; b) CFC1Q/10, após o processo adsortivo de $\mathrm{Cr}$ (III), em pH 5,75; c) CFC1Q/7,5, após o processo adsortivo de Cr (III), em pH 6,5; d) CFC2Q/7,5, após o processo adsortivo de $\mathrm{Cr}$ (III), em pH 6,5.

relacionada ao aumento da faixa granulométrica e com $\mathrm{pH}$ acima de 5,7;

- A homogeneidade da mistura (interação entre os materiais) e a cristalinidade dos materiais compósitos, além das dimensões da FC, da quantidade de Q e do pH da solução de $\mathrm{Cr}$ (III), são fatores que podem modificar a estrutura morfológica das cadeias poliméricas e o caráter iônico dos sítios ativos existentes; consequentemente, influenciaram o processo de adsorção;

- Com o aumento da quantidade de Q e do pH da solução de Cr (III), ocorre uma tendência de aumento da eficiência do processo de adsorção, para as três faixas granulométricas da FC, como mostrado pelas superfícies de resposta geradas pelos modelos matemáticos. 


\section{REFERÊNCIAS}

Abd El-Rehim, H.A.; HEGAZY, E.A.; EL-HAG ALI, A. (2000) Selective removal of some heavy metal ions from aqueous solution using treated polyethylene-g-styrene/maleic anhydride membranes. Reactive \& Functional Polymers, v. 43, p. 105-116.

AKPEROV, O.G.; MAHARRAMOV, A.M.; AKPEROV, E.O.; GARIBOV, A.A. (2O11) The modified co-(heptene-1-maleic anhydride)-polymer as an adsorbent for uranyl ions removal from aqueous solutions. International Journal of Chemical Science and Technology, v. 1, n. 1, p. 11-20.

ALBINANTE, S. R.; PACHECO, E. B. A. V.; VISCONTE, L. L. Y. Revisão dos tratamentos químicos da fibra natural para mistura com poliolefinas. Química Nova, v. 1, n. 36, 2013, p.114-122.

AZEVEDO, B.S.M.; RIZZO, A.C.L.; LEITE, S.G.F.; SOBRAL, L.G.S.; REICHWALD, D.; WALCHAN, G.M. (2008) Utilização da fibra da casca de coco verde como suporte para a formação de biofilme visando o tratamento de efluentes. Rio de Janeiro: CETEM/MCT. 140p. (Série Tecnologia Ambiental 51).

BARONI, P.; VIEIRA, R.S.; SILVA M.G.C.; BEPPU, M.M. (2005) Adsorção de cromo em coluna de leito fixo, utilizando quitosana natural e reticulada. In: Congresso Brasileiro de Engenharia Química em Iniciação Científica, 6., Campinas. Anais... Campinas. p. 1-7.

BRASIL, J.L.; VAGHETTI, J.C.P.; ROYER, B.; SANTOS JR., A.A.; SIMON, N.M.; PAVAN, F.A.; DIAS, S.L.P.; LIMA, E.C. (2007) Planejamento estatístico de experimentos como uma ferramenta para otimização das condições de biossorção de Cu(II) em batelada utilizando-se casca de nozes pecã como biossorvente. Química Nova, v. 30, n. 3, p. 548-553.

CHAVES, J.A.P.(2009) Adsorção de corantes têxteis sobre quitosana: condições, modelagem e otimização. 96p. Tese (Doutorado) Programa de Pós-Graduação em Química, Universidade Federal da Paraíba, João Pessoa.

COUTINHO, F.M.B; COSTA, M.P.M.; GUIMARÃES, M.J.O.C:; SOARES, B.G. (2007) Estudo comparativo de diferentes tipos de polibutadieno na tenacificação de poliestireno. Polímeros: Ciência e Tecnologia, v. 17, n. 4, p. 318-324.

DAI, J.; REN, F.; TAO, C. (2012) Adsorption of Cr(VI) and speciation of $\mathrm{Cr}(\mathrm{VI})$ and $\mathrm{Cr}(\mathrm{III})$ in aqueous solutions using chemically modified chitosan. International Journal of Environmental Research Public Health, v. 9, p. 1757-1770.

GIOVANNINI, J.G.; TAVARES, G.A.; BENDASSOLLI, J.A. (2008) Avaliação das técnicas de precipitação química e encapsulamento no tratamento e destinação conjunta de resíduos líquidos contendo cromo e vidrarias de laboratório. Química Nova, v. 31, n. 3, p. 676-679.

HEMALATHA, R.; CHITRA, R.; RATHINAM, X.R.; SUDHA, P.N. (2O11) Synthesizing and characterization of chitosan graft co polymer: adsorption studies for $\mathrm{Cu}$ (II) and $\mathrm{Cr}(\mathrm{VI})$. International Journal of Environmental Sciences, v. 2, n. 2, p. 805-828.
HERMES, E.; ORSSATTO, F.; HERMES, M.R.; BEAL, A.; GRANATO JÚNIOR, C.A.; FRARE, L.M. (2009) Reciclagem dos banhos residuais de curtimento ao cromo, através da recuperação do mesmo por sedimentação. Revista Brasileira de Produtos Agroindustriais, v. 11, n. 2, p. 171-180.

KALIA, S.; KAITH, B.S.; KAUR, I. (2011) Cellulose fibers bio-and nanopolymer composites: green chemistry and technology. Berlim: Springer. 758p.

KHATTAB, A. F. \& SEDEEQ, S. H. (2O12) Removal of $\mathrm{Cu}^{+2}, \mathrm{Zn}^{+2}$ and $\mathrm{Cd}^{+2}$ from aqueous solution by using ion exchanger derived from sack polypropylene grafted with maleic acid and its derivatives Rafidain journal of Science, v. 23, n. 3, p. 115-127.

KOTAŚ, J. \& STASICKA, Z. Chromium occurrence in the environment and methods of its speciation. Environmental pollution, v. 107, n.3, 2000, p. 263-283.

LIMA, A.C. (2013) Avaliação da remoção de Cr(III) empregando o pseudocaule da bananeira (Musa parasidíaca) como biossorvente. Dissertação (Mestrado) - Programa de Pós-Graduação em Engenharia Química, Universidade Federal Rural do Rio de Janeiro, Rio de Janeiro.

MAGALHÃES, V.H. \& NEVES, M.A.F.S. (2011) Utilização do pericarpo de coco verde (Cocos Nucifera L. - Arecaceae) para a remoção de resíduos de íons cromo (VI) em soluções aquosas. Perspectivas da Ciência e Tecnologia, v. 3, n. 1-2, p. 10-16.

MALTEZ, H.F. (2003) Desenvolvimento de metodologia em sistema em fluxo para especiação e determinação de cromo em água usando sílica gel modificada e espectrometria de absorção atômica em chama. Dissertação (Mestrado) - Programa de Pós-Graduação em Química, Universidade Federal de Santa Catarina, Florianópolis. 74p.

MEIGA, T.O. (2010) Avaliação de metodologias para imobilização covalente de fibronectina em arcabouços de poli(3-hidroxibutirato). Dissertação (Mestrado) - Programa de Pós-Graduação em Engenharia Metalúrgica e de Materiais, Universidade Federal do Rio de Janeiro, Rio de Janeiro. 94p.

MENDONÇA, R.H.; Thiré, R.M.S.M.; COSTA, M.F.; SILVA FILHO, F.C. (2009) Adsorção de fibronectina a arcabouços de polihidroxibutirato aplicáveis à engenharia óssea. Polímeros: Ciência e Tecnologia, v. 19, n. 2, p. 143-148.

MIOR, R.; DUTRA, J.N.B.; CARASEK, E.; MARTENDAL, E. (2013) Desenvolvimento de um método analítico baseado em microextração líquido-líquido para a determinação de cromo (VI) em amostras aquosas com detecção por espectrometria de absorção atômica em chama. Química Nova, v. 36, n. 7.

MOREIRA, S.A.; OLIVEIRA, A.G.; SOUSA, F.W.; NASCIMENTO, R.F.; BRITO, E.S. (2007) Utilização de bagaço de caju como bioadsorvente na remoção de metais pesados de efluente industrial. In: Congresso de Pesquisa e Inovação da Rede Norte Nordeste de Educação Tecnológica, 2., João Pessoa, PB. Anais... João Pessoa. p. 1-10. 
MUCCILLO, R. C. S. T. Caracterização e avaliação de amido nativo e modificado de pinhão mediante provas funcionais e térmicas. 2009. Tese (Doutorado em Engenharia Química). Universidade Federal do Rio Grande do Sul, Porto Alegre, RS.

NOMANBHAY, S.M. \& PALANISAMY, K. (2005) Removal of heavy metal from industrial wastewater using chitosan coated oil palm shell charcoal. Electronic Journal of Biotechnology, v. 8, n. 1, p. 43-53.

OLIVEIRA, R.C.B. \& MARINS, R.V. (2011) Dinâmica de metaistraço em solo e ambiente sedimentar estuarino como um fator determinante no aporte desses contaminantes para o ambiente aquático: revisão. Virtual Química, v. 3, n. 2, p. 88-102.

OLIVEIRA, T. A.; TEIXEIRA, A.; MULINARI, D. R.; GOULART, S. A. S. Avaliação do uso de agente compatibilizante no comportamento mecânico dos compósitos PEBD reforçados com fibras de coco verde. Cadernos UniFOA, n. 14, 2010. Disponível em: http://www.foa. org.br/cadernos/edicao/14/11.pdf.

PINO, G.A.H. (2005) Biossorção de metais pesados utilizando pó da casca de coco verde (Cocos nucifera). Dissertação (Mestrado) Programa de Pós-Graduação em Engenharia Metalúrgica, Pontifícia Universidade Católica do Rio de Janeiro, Rio de Janeiro. 113 p.

PINO, G.H. \& TOREM, M.L. (2011) Aspectos fundamentais da biossorção de metais não ferrosos: estudo de caso. Tecnologia em Metalurgia, Materiais e Mineração, v. 8, n. 1, p. 57-63.

REDIGHIERI, K. I. Estudo de compósitos de partículas de madeira e $P E B D$ reciclado na presença de agentes compatibilizantes. 2006. Dissertação (Mestrado em Engenharia Química). Universidade Federal Rural do Rio de Janeiro, Seropédica. RJ.

ROY, P.K.; RAWAT, A.S.; CHOUDHARY, V.; RAI, P.K. (2004) Synthesis and analytical application of a chelating resin based on a crosslinked styrene/maleic acid copolymer for the extraction of trace-metal ions. Journal of Applied Polymer Science, v. 94, p. 1771-1779.

SALMAH, H. \& AZIEYANTI, A.N. (2O11) Properties of recycled polyethylene/chitosan composites: the effect of polyethylene-graftmaleic anhydride. Journal of Reinforced Plastics and Composites, v. 30, p. 195-202.

SALMORIA, G. V.; AHRENS, C. H.; VILLAMIZAR, F. A.; \& NETTO, A. D. C. S. Influência do desempenho térmico de moldes fabricados com compósito epóxi/alumínio nas propriedades de PP moldado por injeção. Polímeros: Ciência e Tecnologia, v.18, n.3, p. 262-269.

SANDER, M. M. Estudo da ação plastificante de polímero obtido a partir de ácido oleico, em matriz de polipropileno e polietileno. 2010. Trabalho de Conclusão do Curso de Química Industrial. Universidade Federal do Rio Grande do Sul, Pelotas, RS.
SIGNINI, R. \& ARRUDA, A.F.O. (2010) Uso de quitosana e derivados como adsorvente de cromo. Processos Químicos, n. 8, p. 29-37.

SILVA, A.P.O.; MELO, J.V.; MELO, J.L.S.; PEDROZA, M.M. (2O11) Remoção de íons chumbo $\left(\mathrm{Pb}^{2+}\right)$ de efluentes sintéticos através de adsorção em vermiculita revestida com quitosana. Liberato, Novo Hamburgo, v. 12, n. 17, p. 29-38.

SILVA, K.M.D.; REZENDE, L.C.S.H.; SILVA, C.A.; BERGAMASCO, R.; GONÇALVES, D.S. (2013) Caracterização físico-química da fibra de coco verde para a adsorção de metais pesados em efluente de indústria de tintas. Engevista, v. 15, n. 1, p. 43-50.

SOUSA, D.A.; OLIVEIRA, E.; NOGUEIRA, M.C.; ESPÓSITO, B.P. (2O10) Development of a heavy metal sorption system through the $\mathrm{P}=\mathrm{S}$ functionalization of coconut (Cocos nucifera) fibers. Bioresource Technology, v. 101, n. 1, p. 138-143.

SOUZA, J.V.T.M.; MASSOCATTO, C.L.; DINIZ, K.M.; TARLEY, C.R.T.; CAETANO, J.; DRAGUNSKI, D.C. (2012) Adsorção de cromo (III) por resíduos de laranja in natura e quimicamente modificados, Semina: Ciências Exatas e Tecnológicas, Londrina, v. 33, n. 1, p. 3-16.

SOUZA, J.L. (2009) Mesocarpo do coco verde (cocos nucifera) como adsorvente para os corantes: turquesa remazol e azul remazol. Dissertação (Mestrado) - Programa de PósGraduação em Química, Universidade Federal do Maranhão, São Luís. 137p.

TALOKAR, A.Y. (2011) Studies on removal of chromium from waste water by adsorption using low cost agricultural biomass as adsorbents. International Journal of Advanced Biotechnology and Research, v. 2, n. 4, p. 452-456.

TOLEDO, T.V.; BELLATO, C.R.; PESSOA, K.D.; FONTES, M.P.F. (2O13) Remoção de cromo (VI) de soluções aquosas utilizando o compósito magnético calcinado hidrotalcita-óxido de ferro: estudo cinético e de equilíbrio termodinâmico. Química Nova, v. 36, n. 3, p. $419-425$.

UCHOA, P.K.S.; SILVA, D.C.; GOUVEIA S.T. (2007) O uso da fibra de coco para adsorção, separação e especiação de cromo III e VI. In: Congresso Brasileiro de Química, 47., Natal, RN. Anais...

VIANA, A.B. \& GAUBEUR, I. (2009) Avaliação e aplicação de coco verde e cana de açúcar na retenção de níquel e zinco. In: Simpósio de Iniciação Científica da Universidade Federal do ABC, 2., Santo André. Anais...

VIEIRA, R.S. (2004) Remoção e recuperação de íons Hg (II) utilizando quitosana natural e reticulada. 150f. Dissertação (Mestrado) - Programa de Pós-Graduação em Engenharia Química, Universidade Estadual de Campinas, Campinas. 